\title{
Meeting The Needs Of Business: Are We Teaching The Right Things?
}

Robert Christie Mill, (E-mail: rmill@du.edu), University of Denver

\begin{abstract}
It may be that business schools are not providing undergraduate business students with the competencies considered most important by company recruiters. Research from Bentley College and the University of Guelph indicates that graduates and managers find that non-technical skills such as creativity, oral and written communication, decision-making and leadership are least adequately developed in undergraduate business students. A study out of Wake Forest University indicates that recruiters consider the most important competencies for undergraduate business students to have are: Communication and interpersonal skills, Leadership skills and potential, Ability to work effectively within teams, Adaptability, including dealing with ambiguity, People and task management skills, Self-management skills. 'Specific functional expertise' is listed as only of 'medium' importance. Yet the overwhelming majority of undergraduate business courses cover the functional areas of accounting, finance, marketing, management, economics and information technology. A variety of delivery approaches from various undergraduate business programs are examined to determine the best way to cover these important topics.
\end{abstract}

\section{INTRODUCTION}

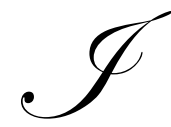

$\mathrm{t}$ may be that business schools are not providing undergraduate business students with the competencies considered most important by company recruiters. Research from Bentley College and the University of Guelph indicates that non-technical skills such as creativity, oral and written communication, decisionmaking and leadership are those graduates and managers find are least adequately developed in undergraduate business students (1).

A study out of Wake Forest University (2) indicates that recruiters consider the most important competencies for undergraduate business students to have are:

- $\quad$ Communication and interpersonal skills

- $\quad$ Leadership skills and potential

- $\quad$ Ability to work effectively within teams

- $\quad$ Adaptability, including dealing with ambiguity

- $\quad$ People and task management skills

- $\quad$ Self-management skills

'Specific functional expertise' is listed as only of 'medium' importance. Yet the overwhelming majority of undergraduate business courses cover the functional areas of accounting, finance, marketing, management, economics and information technology.

\section{DIFFERENT APPROACHES}

It is important to remember that the end result is to produce graduates with the knowledge, skills, abilities and attitudes that employers consider important. A study of best practices indicates a variety of approaches taken to determine and deliver the items. 
Bentley College and the University of Guelph. The approach that Bentley College and the University of Guelph have taken is to focus on four areas - Managing Self, Communicating, Managing People and Tasks and Mobilizing Innovation and Change (3). These four areas are defined as follows:

- $\quad$ Managing Self: “Constantly developing policies and internalizing routines for maximizing one’s ability to deal with the uncertainty of an ever-changing environment." Skills include learning, personal organization/time management, personal strengths and problem solving/analytic.

- $\quad$ Communicating: "Interacting effectively with a variety of individuals and groups to facilitate the gathering, integrating and conveying of information in many forms (e.g. verbal, written)." Skills include interpersonal, listening, oral and written communication.

- $\quad$ Managing People and Tasks: 'Accomplishing the tasks at hand by planning, organizing, coordinating, and controlling both resources and people.” Relevant skills include coordinating, decision-making, leadership influence, managing conflict and planning and organizing.

- $\quad$ Mobilizing Innovation and Change: "Conceptualizing, as well as setting in motion, ways of initiating and managing change that involve significant departures from current mode." This includes the ability to conceptualize, creativity/innovation/change, risk-taking and visioning.

When employers were asked to rate where the greatest need for improvement lay they noted items where graduates rank low and where will be in great demand in the future. In Mobilizing Innovation and Change, the skills are visioning, creativity and risk-taking. In Managing People and Tasks the skills are leadership and managing conflict.

University of Richmond. The approach taken at the University of Richmond is to deliver specific competencies through a Professional Development Program. Six learning outcomes and competencies have been identified (4):

- $\quad$ Critical Thinkers with Sound Judgment - the integration of functional business knowledge into all areas of business.

- $\quad$ Creative Problem Solvers - including reason, think analytically and understand the impact of environmental issues on business.

- $\quad$ Effective Communicators - including writing, presenting, group/team work, negotiation and conflict resolution.

- $\quad$ Effective Change Agents - initiate, lead and manage the change process and adapt to change.

- $\quad$ Ethical Decision Makers - engage in ethical and professional behaviors.

- $\quad$ Respecter of Diversity - recognize, comprehend and discern the importance of demographic, socioeconomic, cultural and intellectual differences.

- $\quad$ Global Awareness - understand the global business environment.

The Program is delivered through four units. The first unit, taken in the second semester of the sophomore year, orients students to the Program, introduces them to the inductive learning process, internship search techniques and service learning. The second unit is taken in the first semester of the junior year includes modules on Increasing Communication Effectiveness, Effective Presentations and Effective Business Writing. In the second semester of the junior year students participate in two half-day professional development seminars on Inclusive Diversity and Global and Cultural Awareness. Additional sessions are offered on Developing Your Portfolio and Professional/Career Development. The final unit is taken in the first semester of the senior year and concentrates on the development and completion of the students' portfolio to demonstrate their competence in the seven areas noted above.

The George Washington University. Many of the items noted above are to be found as part of a career management strategy. The George Washington University has taken the unusual approach of outsourcing its Career Management Services (5). The University has contracted with Lee Hecht Harrison, a global career management firm, to deliver various programs intended to give students the skills demanded by employers. The overall focus of the program involves: 
- $\quad$ Lifelong career management skills

- $\quad$ Awareness of the importance of career development

- $\quad$ Professional development

- $\quad$ Student engagement

- $\quad$ Alumni engagement

The focus in the first year is on self-awareness. Students are introduced to career services and the idea of a 'Senior Resume.' The second year focus is on preparing for an internship. The third year focus is on study abroad while professional preparedness is the major item addressed in the senior year.

\section{FROM BACKPACK TO BRIEFCASE}

A review of the undergraduate curriculum required of business students in the Daniels College of Business at the University of Denver finds that several of the important items noted above are covered in various courses. However many of the items are not to be found in required courses. The overall concept is being implemented under the banner: From Backpack to Briefcase. A three-pronged approach is being tested. Core competencies are being designed to be delivered by way of required courses; a series of activities are planned under Career Management; and a third sequence of units is to be given under Degree Management.

The Degree Management unit will consist of three workshops offered each quarter. They are (6):

\section{Freshmen Education Planning Workshop}

Target Audience: First-Year Business Students

Students will work with academic advising staff to choose a major and create an academic plan to guide them toward graduation. Secondary goals will be to deliver information on campus resources to facilitate adjustment to college life, and create awareness regarding opportunities in the Daniels community.

\section{Understanding Your Academic Progress Report (APR)}

\section{Target Audience: All Business Students}

Utilizing the students’ APR, this workshop will empower students by teaching them how to understand and interpret the document, and use it as a tool to track their progress toward graduation. This workshop and type of training will create long-term opportunities to create a potential pool of peer advisors.

\section{Graduation Planning Workshop}

Target Audience: Senior Business Students

This workshop will cover how to file for graduation and the degree check timeline.

The Core Competencies consist of eight items that target the skills identified by the research above. This list is adapted from work done Green and Seymour (7). Each competency is tied to a specific required course. Acquiring the competency is done outside of class time in workshops. However, acquiring the competency is a part of the grade for that course.

Competencies are linked to appropriate courses. For example the Introduction to Marketing course involves a major group project. The competency The Team Player is a logical place for this unit. 
The competencies are:

- $\quad$ The Great Communicator

o Speak effectively to another individual

o Write factual material clearly and concisely

o Read with comprehension and speed

o Question effectively

o Write persuasively

o Speak effectively to groups

o Listen intently and objectively

o Explain concepts well

o Critique, edit and proofread

o $\quad$ Express feelings appropriately

- $\quad$ The Team Player

o Able to influence others

o Negotiate and compromise

o Withstand and resolve conflict

o Understand the feelings of others

o Encourage debate

o $\quad$ Organize and delegate tasks

o Motivate and develop other people

o Appreciate and reward people's efforts

- $\quad$ The Technology Master

o Be familiar with major hardware components

o $\quad$ Be able to use software packages

o Use information to aid problem solving

o $\quad$ Make graphic presentations

o Access information from many sources

o Transform raw data into useful information

o $\quad$ Communicate using electronic means

- $\quad$ The Problem Solver

o Define problems

o Exhibit intellectual curiosity

o Think abstractly and reflectively

o Distinguish between fact and opinion

o Propose and evaluate solutions

o Possess an open, receptive mind

o Defend a conclusion rationally

o $\quad$ Bring reason to bear on a problem

- $\quad$ The Foreign Ambassador

o $\quad$ Get along with other people

o Be tolerant of other cultures

o $\quad$ Be able to speak foreign languages

o Maintain openness to different ideas

o Develop a global, not an ethnocentric, perspective

o $\quad$ Be aware of cultural differences

o $\quad$ Be able to adjust to new conditions

o $\quad$ Have no fixed prejudices

o $\quad$ Be curious about new situations

o Understand the interdependence of nations in a global economy 


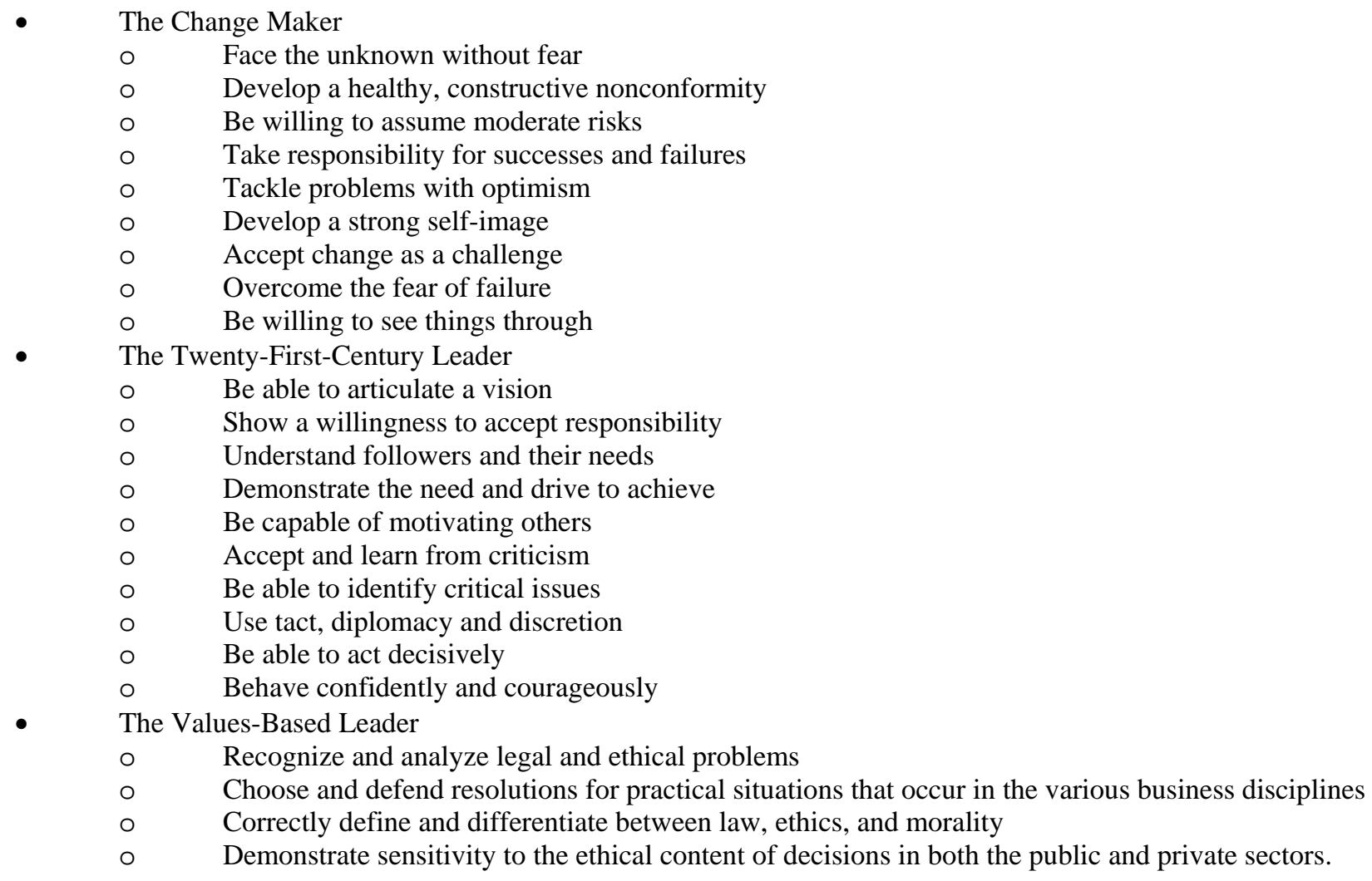

The Career Management unit will consist of activities required for graduation and additional optional activities. The items required for graduation are:

- $\quad$ Career Leader (a business career self-assessment tool)

- $\quad$ Attend a workshop on resume writing

- $\quad$ Participate in a mock interview

Students attend a CareerLeader (CL) Workshop to review their results and discuss career exploration. They perform an active career research assignment which culminates in a brief presentation to a career counselor integrating what they learned with the CL results. As a result the students will identify their interests, abilities and motivators related to functions within business via CL and generate a starting list of potential majors and careers.

After attending a Resume/Cover Letter Workshop students will create a first draft of resume and base cover letter, meet with career counselor to review the draft and end up with a professional resume and cover letter. The Mock Interview Day (MID) consists of meetings with employers on campus who have offered their services in order to prepare for On-Campus Recruiting (OCR).

\section{SUMMARY}

While business programs place most emphasis on teaching specific technical expertise, employers say that students are lacking in non-technical skills such as creativity, oral and written communication, decision-making and leadership. Business programs need to consider how to add these items to the business curriculum in order to better prepare graduates for the world of work. 


\section{REFERENCES}

1. Berdow, Iris and Frederick T. Evers, Competency-Based Education and Assessment: Enhancing Educational Effectiveness and Student Employability, Presentation at 2001 AACSB Undergraduate Conference, Dallas, TX, February 12, 2001.

2. Wayne Calloway School of Business and Accountancy, A Report on Recruiters' Perceptions of Undergraduate Schools and Students, February 2004.

3. Berdow, Iris and Frederick T. Evers, Competency-Based Education and Assessment: Enhancing Educational Effectiveness and Student Employability, Presentation at 2001 AACSB Undergraduate Conference, Dallas, TX, February 12, 2001.

4. Professional Development Program course syllabus accessed from the University of Richmond website. Accessed January 20, 2007.

5. Gowan, Mary, Richard Green, Susan Bennett and Gail DePriest, Outsourcing Career Management Services, Presentation at 2006 AACSB Undergraduate Conference, Scottsdale, AZ, Fall 2006.

6. Internal document from Greg Grauberger, Director of Undergraduate Student Service, Daniels College of Business, University of Denver.

7. Adapted from K.C. Green and D.T. Seymour, Who's Going to Run General Motors? 1964 (publisher unknown).

\section{NOTES}

